\title{
Optimization of Process Parameters for Production of Poly(3-hydroxybutyrate) by Bacillus pumilus AHSD 04, a Seed Borne Endophyte of Oleaginous Plant Arachis
} hypogaea L.

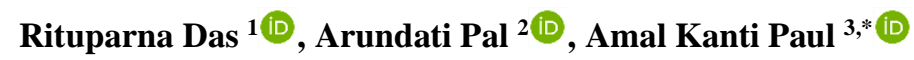 \\ 1 Microbiology Laboratory, Department of Botany, University of Calcutta, 35 Ballygunge Circular Road, Kolkata 700019, \\ West Bengal, India; rituparna0912@yahoo.com (R.D.); \\ 2 Department of Botany, Serampore College, 9 William Carrey Road, Serampore, Hooghly 712201, West Bengal, India; \\ arundhatipalcu@gmail.com (A.P.); \\ 3 Microbiology Laboratory, Department of Botany, University of Calcutta, 35 Ballygunge Circular Road, Kolkata 700019, \\ West Bengal, India; amalk_paul@yahoo.co.in (A.K.P.); \\ * Correspondence: amalk_paul@yahoo.co.in (A.K.P.);
}

Scopus Author ID 35494333700

Received: 19.07.2021; Revised: 28.08.2021; Accepted: 5.09.2021; Published: 18.10.2021

\begin{abstract}
Endophytic bacteria, which thrive inside the plants, synthesize and accumulate intracellular biopolymer polyhydroxyalkanoates (PHAs) to strive against the hostile plant environment. The present study is focused on enhancing the production of poly (3-hydroxybutyrate) $[\mathrm{P}(3 \mathrm{HB})]$, the most common PHA by the seed endophytic bacterium Bacillus pumilus AHSD 04 (GenBank accession number KY038573; MCC accession number 3573) isolated from the oleaginous plant Arachis hypogaea L. Interactions among the three most important influencing variables, glucose, tryptose, and initial $\mathrm{pH}$ affecting growth and $\mathrm{P}(3 \mathrm{HB})$ production were studied using the central composite design (CCD) of response surface methodology $(\mathrm{RSM})$. A 3.94-fold enhancement of $\mathrm{P}(3 \mathrm{HB})$ production $(5.36 \mathrm{~g} / \mathrm{L})$ was achieved over that of the 'one variable at a time' method. The isolate also produced co-polymers of 3hydroxybutyrate (3HB) and 3-hydroxyvalerate (3HV) [P(3HB-co-3HV)] with the incorporation of 4.98 mol\% 3HV during dual-step cultivation using glucose and valeric acid as co-substrate. The polymers, $\mathrm{P}(3 \mathrm{HB})$ and $\mathrm{P}(3 \mathrm{HB}-\mathrm{co}-3 \mathrm{HV})$, so produced have been validated and characterized by Fourier transform infrared (FTIR) and ${ }^{1} \mathrm{H}$ nuclear magnetic resonance $\left({ }^{1} \mathrm{H}\right.$ NMR) spectroscopic analysis. It is apparent that RSM has been successfully established as a promising tool to increase $\mathrm{P}(3 \mathrm{HB})$ yield by the seed endophyte B. pumilus AHSD 04, which can further be utilized to scale up the production of these biodegradable polymers of industrial importance.
\end{abstract}

Keywords: Poly(3-hydroxybutyrate); poly(3-hydroxybutyrate-co-3-hydroxyvalerate); response surface methodology; Bacillus pumilus; Arachis hypogaea $\mathrm{L}$.

(C) 2021 by the authors. This article is an open-access article distributed under the terms and conditions of the Creative Commons Attribution (CC BY) license (https://creativecommons.org/licenses/by/4.0/).

\section{Introduction}

Plants as multicellular hosts provide distinct ecological niches for diverse microorganisms. Endophytes inhabiting the internal tissues of the plants are an essential component of the plant microbiota [1]. Being present inside the plants, endophytes influence the development of the host plant significantly [2]. These endogenously associated microorganisms have also been recognized as chemical synthesizers inside the plants and critically evaluated for their ability to produce an innumerable number of unique chemical 
compounds [3, 4]. Polyhydroxyalkanoates (PHAs), the polyesters of $R$-hydroxyalkanoic acids, are often synthesized and accumulated intracellularly by a wide variety of bacteria and archaea. These intracellular biopolymers serve as carbon and energy reserves and contribute to bacteria's survival in competitive and stressful environments [5]. The endosphere-associated bacterial communities have also been well explored for biosynthesis and intracellular accumulation of PHAs [6, 7]. The PHA biopolymers contribute to colonization and endow survival of the endophytic bacterial communities in the hostile microenvironment inside the host plants $[8,9]$. Recently, Alves et al. [10] have established that the plant growth promotion by the diazotrophic endophytic bacterium Herbaspirillum seropedicae is dependent on PHA metabolism. Moreover, the lack of PHAs in mutant strains of $H$. seropedicae altered the redox balance and increased oxidative stress that significantly affected the expression of several genes [11].

That the internal environments of oleaginous plants provide unique ecological habitats for the growth and sustenance of PHA-accumulating bacteria [12] has been well justified from our laboratory $[13,14]$. The peanut plant (Arachis hypogaea L.), the fourth most important edible oil source of the world [15] has been investigated quite extensively and recognized as a treasured microbial repository $[16,17]$. The seed endophytes, in particular, have gained significant interest as they are transmitted vertically and ensure their presence in progeny plants [18, 19]. While Sobolev et al. [20] have demonstrated the predominance of members of the genus Bacillus as peanut seed endophytes, the antagonistic activity of Bacillus velezensis, a peanut seed borne endophyte, have been documented by Chen et al. [21].

Despite the fact that the endophytic Bacillus spp. are excellent plant growth promoters $[22,23]$ and biocontrol agents [24], their efficacy towards biosynthesis and accumulation of intracellular PHAs have rarely been explored [25]. On the contrary, non-endophytic strains of Bacillus spp. have been recognized as efficient PHA producers [26, 27]. The PHAs produced by Bacillus spp., in general, are free from endotoxins and hence preferred for biomedical applications. However, until now, commercial production of PHAs by Bacillus spp. has met with limited success mainly due to the negative impact of the process of sporulation [28]. While a few Bacillus spp. accumulate poly(3-hydroxybutyrate) [P(3HB)], one of the most common PHAs during the exponential phase of growth; others accumulate the polymer during the late exponential to stationary phase [29]. The $\mathrm{P}(3 \mathrm{HB})$ so accumulated was found to be degraded and utilized at the onset of sporulation [14]. Valappil et al. [30] showed that acidic pH of the medium was responsible for the repression of sporogenesis in Bacillus cereus SPV and thereby enhanced biosynthesis and accumulation of $\mathrm{P}(3 \mathrm{HB})$. Hence, critical evaluation and optimization of fermentation medium and process parameters might promote $\mathrm{P}(3 \mathrm{HB})$ production even at the instance of sporogenesis in Bacillus spp. The parameters such as carbon, nitrogen source, and $\mathrm{pH}$ of the medium have been reported to exert remarkable influence on the production and accumulation of $\mathrm{P}(3 \mathrm{HB})$ [31]. Response surface methodology (RSM) has been established as an efficient statistical tool for analyzing the interactive effect of process parameters involved in fermentation seeking optimized conditions for improved product yield $[32,33]$.

The endophytic existence of Bacillus pumilus is not new and has already been documented in various plant species [23, 34, 35]; however, intracellular accumulation of $\mathrm{P}(3 \mathrm{HB})$ in such endogenously associated B. pumilus strains is of rare occurrence [36]. We, from this laboratory, have reported the isolation of a new endophytic strain designated as Bacillus pumilus AHSD 04 from seeds of oleaginous plant Arachis hypogaea L., and have documented the biosynthesis and intracellular agglomeration of $\mathrm{P}(3 \mathrm{HB})$ by this strain under 
batch cultivation [37]. The present study is an attempt to optimize the physicochemical process parameters and nutritional factors for $\mathrm{P}(3 \mathrm{HB})$ production by the endophytic $B$. pumilus AHSD 04 following response surface methodology (RSM). Furthermore, the production of a copolymer of 3-hydroxybutyrate and 3-hydroxy valerate [P(3HB-co-3HV)] by the strain has also been achieved following the dual-step cultivation process.

\section{Materials and Methods}

\subsection{Bacterial strain and maintenance.}

Bacillus pumilus AHSD 04 (GenBank accession number KY038573; MCC accession number 3573), a seed-borne endophyte of oleaginous plant Arachis hypogaea L., isolated and reported from this laboratory [37] was used throughout the present study. The endophytic isolate was grown on the slopes of tryptic soy agar at $32{ }^{\circ} \mathrm{C}$ for $24 \mathrm{~h}$ and maintained on the same medium by sub-culturing at a regular interval of one month.

\subsection{Culture condition.}

The endophytic bacterial isolate AHSD 04 was grown in modified mineral salts (MS) medium [38] supplemented with tryptose for growth and $\mathrm{P}(3 \mathrm{HB})$ production. The medium (20 $\mathrm{mL} / 100 \mathrm{~mL}$ flask) was inoculated (at $1 \%$ level) with freshly grown culture and incubated at 32 ${ }^{\circ} \mathrm{C}$ on a rotary shaker $(120 \mathrm{rpm})$ for $72 \mathrm{~h}$.

\subsection{Estimation of growth.}

For estimation of growth, the cell mass from the growing culture was harvested by centrifugation $(12000 \times g$ for $10 \mathrm{~min})$, washed thrice with deionized water, and subsequently, the dry weight was determined following drying to a constant weight at $80{ }^{\circ} \mathrm{C}$.

\subsection{Quantification of $P(3 H B)$.}

The intracellular $\mathrm{P}(3 \mathrm{HB})$ was extracted from the dried cell mass $(2 \mathrm{mg})$ with warm chloroform (40-45 ${ }^{\circ} \mathrm{C}$ ) and quantified according to the crotonic acid assay method [39]. The polymer extracted from the dried cell mass was transformed to crotonic acid succeeding treatment with $\mathrm{H}_{2} \mathrm{SO}_{4}$ in a boiling water bath for $10 \mathrm{~min}$, cooled to room temperature, and subjected to UV spectral analysis. The absorbance of the treated polymer was scanned in the range of 200-300 nm in a UV-VIS spectrophotometer (Jenway, Model 6505) using analytical grade chloroform as the blank, and the absorbance at $235 \mathrm{~nm}$ was determined. The $\mathrm{P}(3 \mathrm{HB})$ content of the cell mass was determined from the calibration curve prepared according to the same method using the original $\mathrm{P}(3 \mathrm{HB})$ from Sigma-Aldrich (USA); the total PHA was determined by the gravimetric method.

\subsection{Extraction and purification of the polymer.}

The intracellularly accumulated polymer was extracted from the thoroughly washed and dried cell mass with chloroform at $40-45{ }^{\circ} \mathrm{C}$ for $2-4 \mathrm{~h}$, and the process was repeated thrice. The chloroform extracts were pooled, filtered through glass wool, concentrated under reduced pressure, and precipitated the crude polymer with double volumes of pre-chilled diethyl ether. The precipitate was collected by centrifugation $(16,000 \times g$ for $12 \mathrm{~min})$, washed with acetone and ethanol, re-dissolved in chloroform, and the pure polymer was recovered following 
precipitation with chilled diethyl ether. Finally, the precipitate was obtained by centrifugation $(16,000 \times g$ for $12 \mathrm{~min})$, air-dried, and the white powdery mass was stored in a desiccator for further use.

\subsection{Process optimization for $P(3 H B)$ production.}

\subsubsection{Experimental design.}

The Central composite design (CCD) of response surface methodology (RSM) was principally followed to determine the optimum levels and elucidate the interaction among the independent variables viz. carbon source (glucose), nitrogen source (tryptose), and initial $\mathrm{pH}$ of the medium, which significantly influence the growth and $\mathrm{P}(3 \mathrm{HB})$ production. The values of the remaining variables (incubation time, temperature, inoculum volume, agitation, etc.) were maintained at a constant level. The CCD experiments were formulated in 20 trial runs using the Design-Expert software (version 13.0.1.0) (Stat-Ease, Inc. MN, USA). The three independent variables (glucose, tryptose and $\mathrm{pH})$ were used at five coded levels $(-\alpha,-1,0,+1$, $+\alpha)(\alpha=1.682)$ including six axial points, eight factorial points and six central points. All the experiments based on the CCD were performed in triplicate.

Real levels of the independent variables were coded according to the following equation:

$\mathrm{Z}=\left(\mathrm{Zi}_{\mathrm{i}}-\mathrm{Z}_{0}\right) / \Delta \mathrm{Z}$

where, $Z$ is the dimensionless coded value, and $Z i$ is the real value of the independent variable; $Z_{0}$ indicates the value of the independent variable at the central point, and $\Delta Z$ represents the step change value.

The data obtained from the design were analyzed by multiple regression analysis using the following second-order polynomial equation (2) for two response variables [growth and $\mathrm{P}(3 \mathrm{HB})$ production]:

$Y=\beta_{0}+\beta_{1} X_{1}+\beta_{2} X_{2}+\beta_{3} X_{3}+\beta_{12} X_{1} X_{2}+\beta_{13} X_{1} X_{3}+\beta_{23} X_{2} X_{3}+\beta_{11} X_{1}^{2}+\beta_{22} X_{2}^{2}+\beta_{33} X_{3}^{2}$

where, $\mathrm{Y}$ represents the predictive response variable, $\mathrm{X}_{1}, \mathrm{X}_{2}, \mathrm{X}_{3}$ are the coded values of three independent variables, i.e., glucose, tryptose, and $\mathrm{pH}$, respectively, $\beta_{1}, \beta_{2}$, and $\beta_{3}$ are linear coefficients, $\beta_{12}, \beta_{13}$, and $\beta_{23}$ are interactive cross-product coefficients, $\beta_{11}, \beta_{22}$, and $\beta_{33}$ are quadratic coefficients, and $\beta_{0}$ is the constant.

\subsubsection{Statistical analysis.}

Interaction between the independent variables and their effect on growth $\left(\mathrm{Y}_{1}\right)$ as well as PHA production $\left(\mathrm{Y}_{2}\right)$ were inferred from the three-dimensional response surface plots. These plots were prepared by plotting the individual responses [growth and $\mathrm{P}(3 \mathrm{HB})$ production] on the $\mathrm{Z}$-axis against any two selected independent variables within their experimental range while holding the other independent variables at a constant level. Validation of the statistical model was executed using the point prediction tool of RSM. To validate the model and rationalize the predicted values of the response variables, a test in triplicate was performed using the optimum estimates of independent variables. Statistical analysis and consistency of the model were evaluated by analysis of variance (ANOVA). The statistical significance of the model equation and the model terms were determined by Fischer's $F$ test. The $F$-value was checked to determine the significance of the fitted equations and terms at a 5\% level and represented as a $p$-value $(p<0.05)$. The adequacy of the model was checked by the coefficient of determination 
$\left(\mathrm{R}^{2}\right)$ as well as adjusted $\mathrm{R}^{2}$. The statistical accuracy of the model was resolved through the lack of fit (LOF) assessment.

\subsection{Dual-step cultivation for co-polymer production.}

A dual-step cultivation methodology [6] has opted for the synthesis of co-polymers. Initially, the endophytic isolate was grown in a modified mineral salts medium containing glucose $(37.7 \mathrm{~g} / \mathrm{L})$ and tryptose $(4.3 \mathrm{~g} / \mathrm{L})$ under continuous shaking at $32{ }^{\circ} \mathrm{C}$. Cells from actively growing culture ( $24 \mathrm{~h}$ old) were collected aseptically by centrifugation $(12,000 \times \mathrm{g}$ for $10 \mathrm{~min}$ ) at $4{ }^{\circ} \mathrm{C}$, washed with sterile normal saline, and immediately transferred to the same fresh medium containing valeric acid $(0.05-0.5 \%$, w/v) as co-substrate and incubated under continuous shaking $(120 \mathrm{rpm})$ at $32{ }^{\circ} \mathrm{C}$ for $48 \mathrm{~h}$.

\subsection{Characterization of polymers.}

\subsubsection{Fourier transform infrared spectroscopy.}

The extracted and purified homo- and co-polymers $(5 \mathrm{mg})$ were thoroughly mixed with spectroscopic grade $\mathrm{KBr}(100 \mathrm{mg})$ individually and pelletized. The functional groups of the isolated polymers were analyzed by Fourier transform infrared (FTIR) spectroscopy using a Bruker FTIR spectrophotometer in the range of 4000 to $400 \mathrm{~cm}^{-1}$.

\subsubsection{Nuclear magnetic resonance spectroscopy.}

The chemical structure of the isolated homo- and co-polymers was interpreted based on proton nuclear magnetic resonance $\left({ }^{1} \mathrm{H} \mathrm{NMR}\right)$ spectroscopic analysis. The polymer $(5 \mathrm{mg})$ samples were dissolved in $\mathrm{x}$ deuterated chloroform $(1 \mathrm{~mL})$ and subjected to analysis in a Bruker ${ }^{1} \mathrm{H}$ NMR (300 MHz) spectrophotometer. A multinucleate probe head at a 30-degree flip angle was used. The chemical shifts were represented on $\delta$ scale [parts per million (ppm)], and tetramethylsilane $\left(\mathrm{Me}_{4} \mathrm{Si}\right)$ was used as the internal standard.

\section{Results and Discussion}

The seed-borne endophytic bacterium B. pumilus AHSD 04 produced $\mathrm{P}(3 \mathrm{HB})$, accounting $52.3 \%$ of its cell dry weight (CDW) when grown under batch cultivation in glucose $(2 \%, \mathrm{w} / \mathrm{v})$ containing mineral salts medium. Production of $\mathrm{P}(3 \mathrm{HB})$ was further enhanced $(55.2 \%)$ by supplementation of tryptose $(0.2 \%, \mathrm{w} / \mathrm{v})$ and maintenance of the growth medium at pH 7.2 [37]. During the present optimization study, the influencing factors such as carbon (glucose), nitrogen source (tryptose) as well as $\mathrm{pH}$ of the medium have been prudently chosen, keeping the values of remaining factors (incubation time, temperature, inoculum volume, agitation, etc.) at a constant level.

\subsection{Optimization of $P(3 H B)$ production by response surface methodology.}

\subsubsection{Fitting the model.}

A three-variable-five-level design of CCD was employed to determine the optimum conditions of independent variables and their interactive effect for growth $\left(\mathrm{Y}_{1}\right)$ as well as $\mathrm{P}(3 \mathrm{HB})$ production $\left(\mathrm{Y}_{2}\right)$. Glucose $\left(\mathrm{X}_{1}\right)$, tryptose $\left(\mathrm{X}_{2}\right)$ and initial $\mathrm{pH}\left(\mathrm{X}_{3}\right)$ of the medium were 
selected as the independent variables and used at five coded levels $(-\alpha,-1,0,+1,+\alpha)(\alpha=1.682)$ (Table 1).

Table 1. Independent variables and their corresponding coded levels for growth and $\mathrm{P}(3 \mathrm{HB})$ production by $B$. pumilus AHSD 04 based on central composite design (CCD) of response surface methodology (RSM).

Independent variable

Glucose $(\mathrm{g} / \mathrm{L})$

Tryptose $(\mathrm{g} / \mathrm{L})$

$\mathrm{pH}$

\begin{tabular}{|l|l} 
& Symbol \\
& $\mathrm{X}_{1}$ \\
\hline $\mathrm{X}_{2}$ \\
$\mathrm{X}_{3}$
\end{tabular}

Coded levels

The experimental results of growth and $\mathrm{P}(3 \mathrm{HB})$ production based on $\mathrm{CCD}$ model of RSM were presented in Table 2. Coefficients of the polynomial equation were computed from the experimental data to predict the values of the response variables $\left(\mathrm{Y}_{1}\right.$ and $\left.\mathrm{Y}_{2}\right)$. Regression equations for each response variable obtained from RSM are as follows:

$\mathrm{Y}_{1}=6.664+0.843 \mathrm{X}_{1}+0.794 \mathrm{X}_{2}+0.716 \mathrm{X}_{3}-0.35 \mathrm{X}_{1} \mathrm{X}_{2}+0.15 \mathrm{X}_{1} \mathrm{X}_{3}+0.3 \mathrm{X}_{2} \mathrm{X}_{3}-0.821 \mathrm{X}_{1}^{2}-0.927 \mathrm{X}_{2}^{2}-0.645 \mathrm{X}_{3}^{2}$

$\mathrm{Y}_{2}=74.77+11.415 \mathrm{X}_{1}+2.593 \mathrm{X}_{2}+1.719 \mathrm{X}_{3}+0.638 \mathrm{X}_{1} \mathrm{X}_{2}-1.463 \mathrm{X}_{1} \mathrm{X}_{3}-2.838 \mathrm{X}_{2} \mathrm{X}_{3}-9.776 \mathrm{X}_{1}^{2}-7.813 \mathrm{X}_{2}^{2}-3.695 \mathrm{X}_{3}^{2}$

where, $X_{1}, X_{2}, X_{3}$ are the coded values of three independent variables glucose, tryptose, and $\mathrm{pH}$, respectively.

The predicted values for growth as well as $\mathrm{P}(3 \mathrm{HB})$ production were calculated using the regression analysis and correlated with the experimental data, which revealed that the actual response values were in good agreement with the predicted response values. The predicted versus actuals plots for both the responses $\left(\mathrm{Y}_{1}\right.$ and $\left.\mathrm{Y}_{2}\right)$ are represented in Figure 1a and $1 \mathrm{~b}$, respectively.
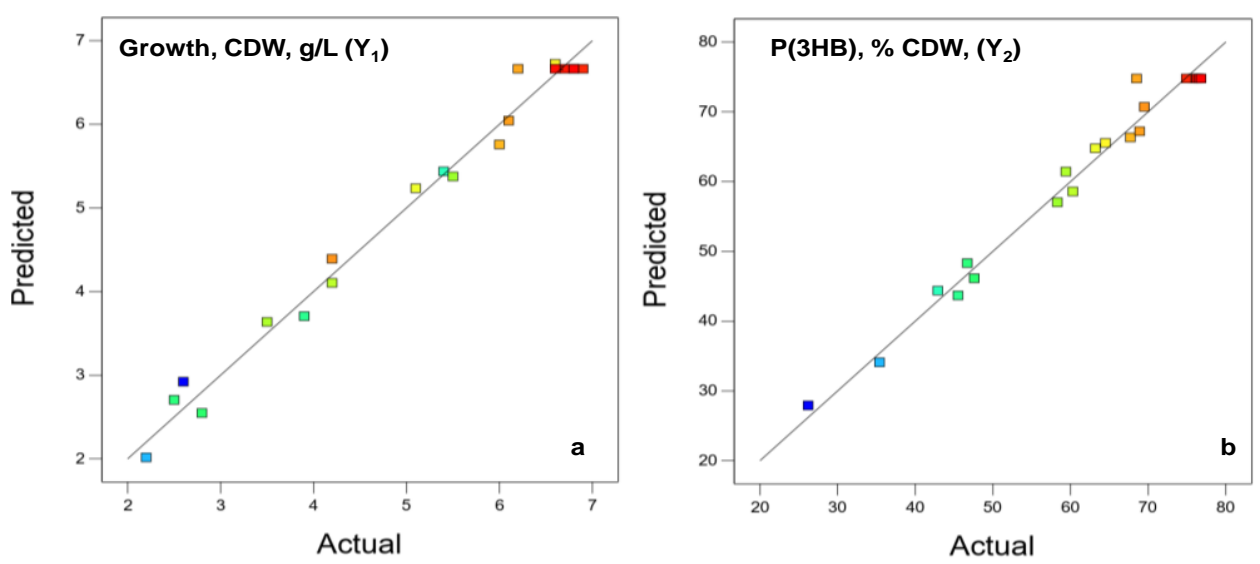

Figure 1. Predicted $v s$ actual plot for (a) growth and (b) $\mathrm{P}(3 \mathrm{HB})$ production by B. pumilus AHSD 04.

Table 2. Experimental design based on central composite design (CCD) of response surface methodology (RSM) and observed responses for growth and $\mathrm{P}(3 \mathrm{HB})$ production by $B$. pumilus AHSD 04.

\begin{tabular}{l|c|c|c|c|c}
\multirow{2}{*}{ Run order } & \multicolumn{3}{|c|}{ Independent variables } & \multicolumn{2}{c}{ Responses } \\
\cline { 2 - 6 } & $\begin{array}{c}\text { Glucose } \\
(\mathbf{g} / \mathbf{L})\end{array}$ & $\begin{array}{c}\text { Tryptose } \\
(\mathbf{g} / \mathbf{L})\end{array}$ & $\mathbf{p H}$ & $\begin{array}{c}\text { Growth, } \\
\mathbf{C D W}, \mathbf{g} / \mathbf{L}\end{array}$ & $\begin{array}{c}\mathbf{P}(\mathbf{3 H B}), \\
\text { \% CDW }\end{array}$ \\
\hline 1 & 40 & 6 & 6 & $4.2 \pm 0.3$ & $69.5 \pm 2.1$ \\
\hline 2 & 30 & 0.64 & 6.5 & $2.5 \pm 0.2$ & $46.7 \pm 1.3$ \\
\hline 3 & 40 & 2 & 7 & $5.1 \pm 0.2$ & $63.2 \pm 1.8$ \\
\hline 4 & 20 & 6 & 7 & $5.4 \pm 0.2$ & $42.9 \pm 0.8$ \\
\hline 5 & 30 & 4 & 6.5 & $6.2 \pm 0.4$ & $68.5 \pm 1.7$ \\
\hline 7 & 20 & 2 & 6 & $2.2 \pm 0.2$ & $35.4 \pm 2.2$ \\
\hline 8 & 46.82 & 4 & 6.5 & $6 \pm 0.1$ & $67.7 \pm 0.8$ \\
\hline 9 & 30 & 7.36 & 6.5 & $5.5 \pm 0.1$ & $58.3 \pm 2.4$ \\
\hline
\end{tabular}




\begin{tabular}{l|c|c|c|c|c}
\multirow{2}{*}{ Run order } & \multicolumn{3}{|c}{ Independent variables } & \multicolumn{2}{c}{ Responses } \\
\cline { 2 - 6 } & $\begin{array}{c}\text { Glucose } \\
(\mathbf{g} / \mathbf{L})\end{array}$ & $\begin{array}{c}\text { Tryptose } \\
(\mathbf{g} / \mathbf{L})\end{array}$ & $\mathbf{p H}$ & $\begin{array}{c}\text { Growth, } \\
\mathbf{C D W}, \mathbf{g} / \mathbf{L}\end{array}$ & $\begin{array}{c}\mathbf{P}(\mathbf{3 H B}), \\
\mathbf{\%}\end{array}$ \\
\hline & 13.18 & 4 & 6.5 & $2.6 \pm 0.4$ & $26.2 \pm 0.8$ \\
\hline 10 & 40 & 2 & 6 & $4.2 \pm 0.1$ & $60.3 \pm 1.2$ \\
\hline 11 & 20 & 2 & 7 & $2.8 \pm 0.1$ & $47.6 \pm 1.6$ \\
\hline 12 & 20 & 6 & 7 & $3.9 \pm 0.5$ & $45.5 \pm 1.1$ \\
\hline 14 & 40 & 6 & 7.3 & $6.6 \pm 0.4$ & $64.5 \pm 0.9$ \\
\hline 15 & 30 & 4 & 6.5 & $6.8 \pm 0.1$ & $68.9 \pm 1.0$ \\
\hline 16 & 30 & 4 & 6.5 & $6.6 \pm 0.2$ & $76.2 \pm 0.8$ \\
\hline 17 & 30 & 4 & 6.5 & $6.9 \pm 0.1$ & $74.9 \pm 1.1$ \\
\hline 18 & 30 & 4 & 6.5 & $6.7 \pm 0.1$ & $75.8 \pm 1.2$ \\
\hline 20 & 30 & 4 & 6.5 & $6.8 \pm 0.1$ & $76.5 \pm 0.5$ \\
& 30 & 4 & & &
\end{tabular}

The significance of the model for growth as well as $\mathrm{P}(3 \mathrm{HB})$ production was evaluated following the execution of analysis of variance (ANOVA) (Table 3). The ANOVA of both the regression models confirmed their significance $\left(F_{\text {model }}>1\right.$, significant $)$ [40] for analyzing the interactive effect of independent variables for biomass formation $\left(\mathrm{Y}_{1}\right)$ and $\mathrm{P}(3 \mathrm{HB})$ production $\left(\mathrm{Y}_{2}\right)$. The $F$ model values were 73.31 and 55.22 for growth and PHA production, respectively, as calculated from the Fisher's $F$-test. The lack of fit was non-significant $(\mathrm{p} \leq 0.05)$ relative to pure error for both the response variables ( $\mathrm{Y}_{1}$ and $\left.\mathrm{Y}_{2}\right)$, which indicated that the models were statistically accurate and sufficient to predict the response variables under any combination of values.

The coefficient of determination $\left(R^{2}\right)$ for $Y_{1}$ and $Y_{2}$ were recorded as 0.9851 and 0.9803 , respectively. The $R^{2}$ is the measure of goodness of fit, and the value varies between 0 and 1 . The closer the $\mathrm{R}^{2}$ to unity, the stronger the model and better it predicts the response [41]. On the other end, lower $\mathrm{R}^{2}$ values indicate that the response variables are not appropriate to explain the variation. The $\mathrm{R}^{2}$ values in the present study demonstrated that both the models could explain more than $98 \%$ variability in biomass $\left(\mathrm{Y}_{1}\right)$ and $\mathrm{P}(3 \mathrm{HB})\left(\mathrm{Y}_{2}\right)$ production. The adjusted $\mathrm{R}^{2}$, which corrects the $\mathrm{R}^{2}$ value for the sample size and the number of terms, were 0.9716 and 0.9625 for $Y_{1}$ and $Y_{2}$, respectively.

Table 3. Analysis of variance (ANOVA) based on quadratic polynomial model.

Growth, CDW (g/L) (Y 1 )

\begin{tabular}{|c|c|c|c|c|c|}
\hline Source & Sum of squares & $\begin{array}{l}\text { Degree of } \\
\text { freedom }\end{array}$ & Mean square & $F$-value & $p$-value \\
\hline Model & 50.81 & 9 & 5.65 & 73.31 & $<0.0001 * * *$ \\
\hline $\mathrm{X}_{1}$ & 9.71 & 1 & 9.71 & 126.14 & $<0.0001 * * *$ \\
\hline $\mathrm{X}_{2}$ & 8.61 & 1 & 8.61 & 111.83 & $<0.0001 * * *$ \\
\hline $\mathrm{X}_{3}$ & 6.99 & 1 & 6.99 & 90.81 & $<0.0001 * * *$ \\
\hline $\mathrm{X}_{1} \mathrm{X}_{2}$ & 0.9800 & 1 & 0.9800 & 12.73 & $0.0051 * * *$ \\
\hline $\mathrm{X}_{1} \mathrm{X}_{3}$ & 0.1800 & 1 & 0.1800 & 2.34 & 0.1573 \\
\hline $\mathrm{X}_{2} \mathrm{X}_{3}$ & 0.7200 & 1 & 0.7200 & 9.35 & $0.0121 * *$ \\
\hline $\mathrm{X}_{1}^{2}$ & 9.72 & 1 & 9.72 & 126.25 & $<0.0001 * * *$ \\
\hline $\mathrm{X}_{2}^{2}$ & 12.40 & 1 & 12.40 & 160.96 & $<0.0001 * * *$ \\
\hline $\mathrm{X}_{3}{ }^{2}$ & 5.99 & 1 & 5.99 & 77.75 & $<0.0001 * * *$ \\
\hline Residual & 0.7701 & 10 & 0.0770 & & \\
\hline${ }^{\mathrm{a}}$ Lack of fit & 0.4568 & 5 & 0.0914 & 1.46 & 0.3446 \\
\hline Pure error & 0.3133 & 5 & 0.0627 & & \\
\hline Cor Total & 51.58 & 19 & & & \\
\hline \multicolumn{6}{|c|}{$\mathrm{P}(3 \mathrm{HB})$ production $(\%, \mathrm{CDW})\left(\mathrm{Y}_{2}\right)$} \\
\hline Model & 4120.27 & 9 & 457.81 & 55.22 & $<0.0001 * * *$ \\
\hline $\mathrm{X}_{1}$ & 1779.55 & 1 & 1779.55 & 214.66 & $<0.0001 * * *$ \\
\hline $\mathrm{X}_{2}$ & 91.81 & 1 & 91.81 & 11.07 & $0.0076^{* * *}$ \\
\hline $\mathrm{X}_{3}$ & 40.36 & 1 & 40.36 & 4.87 & 0.0519 \\
\hline $\mathrm{X}_{1} \mathrm{X}_{2}$ & 3.25 & 1 & 3.25 & 0.3922 & 0.5452 \\
\hline $\mathrm{X}_{1} \mathrm{X}_{3}$ & 17.11 & 1 & 17.11 & 2.06 & 0.1813 \\
\hline
\end{tabular}



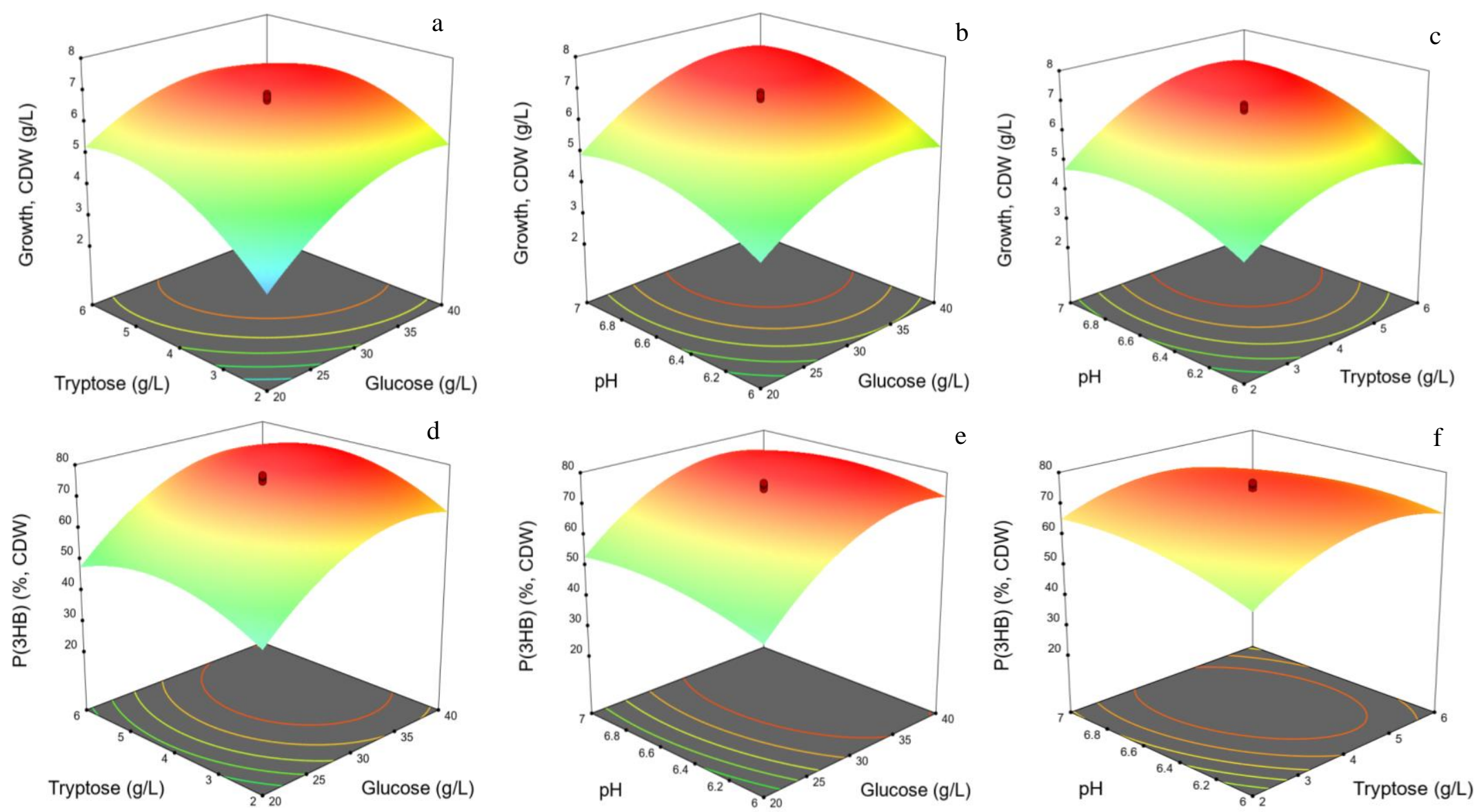

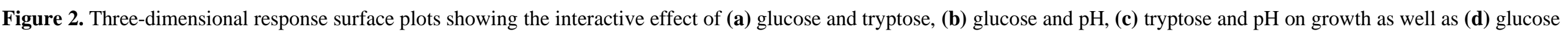
and tryptose, (e) glucose and $\mathrm{pH}$, (f) tryptose and $\mathrm{pH}$ on $\mathrm{P}(3 \mathrm{HB})$ production by B. pumilus AHSD 04 . 


\subsubsection{Validation and confirmation of the model.}

Validation of the statistical model was executed using the point prediction tool of RSM where the optimum values of all three independent variables, i.e., glucose ( $37.7 \mathrm{~g} / \mathrm{L})$, tryptose $(4.3 \mathrm{~g} / \mathrm{L})$, and initial $\mathrm{pH}$ (6.8), were employed for experimentation (Table 4). The experimental values for growth $\left(\mathrm{Y}_{1}\right)$ and $\mathrm{P}(3 \mathrm{HB})$ production $\left(\mathrm{Y}_{2}\right)$ (mean of 3 replicates) were compared with the corresponding predicted values. The actual biomass production $(7.0 \mathrm{~g} / \mathrm{L})$ under optimized conditions was very close to the predicted value $(7.2 \mathrm{~g} / \mathrm{L})$. Likewise, the experimental and predicted values for $\mathrm{P}(3 \mathrm{HB})$ production were $76.5 \%$ and $77.2 \%$ of CDW, respectively. Such closeness of values indicated both validity and suitability of the model.

'One variable at a time' (OVAT) method of optimization involves testing a single variable at a time, keeping the other variables constant. Following OVAT methodology, the isolate AHSD 04 produced biomass of $2.55 \mathrm{~g} / \mathrm{L}$ with $\mathrm{P}(3 \mathrm{HB})$ content of $53.2 \%$, CDW when glucose and tryptose were used as carbon and nitrogen sources, respectively [37]. The conventional single factor system of analysis is time-consuming, especially for many variables, and does not ensure the determination of exact optimal conditions. As an alternative, experimental designs based on statistical models have gained importance as economical and practical solutions for process optimization of various biomaterial productions. The response surface methodology (RSM) has been implemented as a powerful device to improve the production of $\mathrm{P}(3 \mathrm{HB})$ by a wide variety of bacteria [27, 41]. In this study, the central composite design (CCD) was applied for determining the optimum levels of three independent variables glucose, tryptose, and initial $\mathrm{pH}$ of the medium for growth and $\mathrm{P}(3 \mathrm{HB})$ production. The maximum growth $(7.0 \mathrm{~g} / \mathrm{L})$ and $\mathrm{P}(3 \mathrm{HB})$ production $(76.5 \%, \mathrm{CDW})$ were achieved under the optimized conditions of glucose $(37.7 \mathrm{~g} / \mathrm{L})$, tryptose $(4.3 \mathrm{~g} / \mathrm{L})$, and at initial $\mathrm{pH}$ of 6.8 . It was apparent that statistical method-based experimental design has enhanced the $\mathrm{P}(3 \mathrm{HB})$ yield by 3.94 fold (1.36 to $5.36 \mathrm{~g} / \mathrm{L}$ ) as compared to conventional OVAT methodology [37].

Table 4. Optimum values of the independent variables and confirmatory trials for the predicted responses under optimal conditions.

\begin{tabular}{l|l|l}
\multirow{2}{*}{ Independent variable } & Optimum conditions & Actual Level \\
\cline { 2 - 3 } & Coded level & 37.7 \\
\hline Glucose $(\mathrm{g} / \mathrm{L})$ & 0.39 & 4.3 \\
\hline Tryptose $(\mathrm{g} / \mathrm{L})$ & 0.08 & 6.8 \\
\hline $\mathrm{pH}$ & 0.3 & Experimental value \\
\hline Response & Predicted value & $7.0 \pm 0.1$ \\
\hline Growth, CDW $(\mathrm{g} / \mathrm{L})$ & 7.2 & $76.5 \pm 1.4$
\end{tabular}

Each experimental value represents the mean of 3 replicates \pm SD

The coded levels of the independent variables were calculated as: $Z=\left(Z_{i}-Z_{0}\right) / \Delta Z$, where $Z$ is the coded value and $\mathrm{Zi}$ is the real value; $\mathrm{Z}_{0}$ indicates the value of the independent variable at the central point, and $\Delta \mathrm{Z}$ represents the step change value

The intracellular accumulation of $\mathrm{P}(3 \mathrm{HB})$ by the isolate $B$. pumilus AHSD 04 supported earlier observations of biopolymer accumulation by diverse endophytic bacterial species derived from multiple plant sources [42-44]. While reports on $\mathrm{P}(3 \mathrm{HB})$ production by endophytic B. pumilus strains appear to be rare, the potential of non-endophytic B. pumilus strains to produce the biopolymer has been well recognized $[45,46]$. The results obtained from this study appeared to be quite satisfactory when the $\mathrm{P}(3 \mathrm{HB})$ yield $(5.36 \mathrm{~g} / \mathrm{L})$ by endophytic $B$. pumilus AHSD 04 was compared with other non-endophytic strains of B. pumilus. The bacterium $B$. pumilus $\mathrm{H} 9$, isolated from municipal wastes, accumulated $2.47 \mathrm{~g} / \mathrm{L}$ of $\mathrm{P}(3 \mathrm{HB})$ 
following optimization by a four-factor central composite design of RSM [45]. Similarly, $B$. pumilus E10 derived from the urban wastewater yielded approximately $6 \mathrm{mg}$ of $\mathrm{P}(3 \mathrm{HB})$ following consumption of $2.5 \mathrm{~g} / \mathrm{L}$ glucose [46]. Furthermore, these findings also corroborated the $\mathrm{P}(3 \mathrm{HB})$ accumulation in $B$. megaterium [47] and B. mycoides [26], where organic nitrogen source (protease peptone) was found to enhance the intracellular biopolymer production.

\subsection{Production of co-polymers.}

As against the production of $\mathrm{P}(3 \mathrm{HB})$ by Bacillus spp., synthesis and accumulation of PHA co-polymers are restricted to few selective species only [48, 49]. It is well established that the addition of alkanoic acids as co-substrate during dual step cultivation triggers the synthesis of co-polymers [6]. In this study, a dual-step cultivation method was adopted for the production of co-polymers by the endophytic isolate B. pumilus AHSD 04. Cells from exponentially growing culture of AHSD 04 in mineral salts medium containing glucose (37.7 $\mathrm{g} / \mathrm{L})$ and tryptose $(4.3 \mathrm{~g} / \mathrm{L})$, were harvested aseptically, washed in sterile saline, and used to inoculate the same fresh medium with additional supplementation of valeric acid as cosubstrate. After $48 \mathrm{~h}$ of growth, the intracellular accumulation of polymers showed incorporation of 3-hydroxyvalerate $(3 \mathrm{HV})$ in the PHA chain leading to the production of copolymers of $3 \mathrm{HB}$ and $3 \mathrm{HV}$ [P(3HB-co-3HV)]. Variation in concentration of valeric acid $(0.05-$ $0.5 \% \mathrm{w} / \mathrm{v})$ revealed maximum biomass $(6.4 \mathrm{~g} / \mathrm{L})$ and PHA production $(76.1 \%, \mathrm{CDW})$ at the lowest concentration of valeric acid $(0.05 \%)$ tested. The $\mathrm{P}(3 \mathrm{HB}-\mathrm{co}-3 \mathrm{HV})$ so produced showed incorporation of only $2.52 \mathrm{~mol} \% 3 \mathrm{HV}$ (Table 5). On the contrary, growth $(5 \mathrm{~g} / \mathrm{L})$, as well as co-polymer production $(65.6 \%, \mathrm{CDW})$, were comparatively low at $0.3 \%$ valeric acid, but the $3 \mathrm{HV}$ incorporation in the co-polymer appeared to be maximum $(4.98 \mathrm{~mol} \%)$. Further increase in valeric acid concentration showed a prominent negative impact on growth, PHA accumulation as well as $3 \mathrm{HV}$ incorporation. As far as we are aware, this appears to be the first report of co-polymer accumulation by $B$. pumilus strain.

Table 5. Influence of valeric acid as co-substrate on growth, production and composition of PHA accumulated by the endophytic bacterium B. pumilus AHSD 04 during dual-step cultivation.

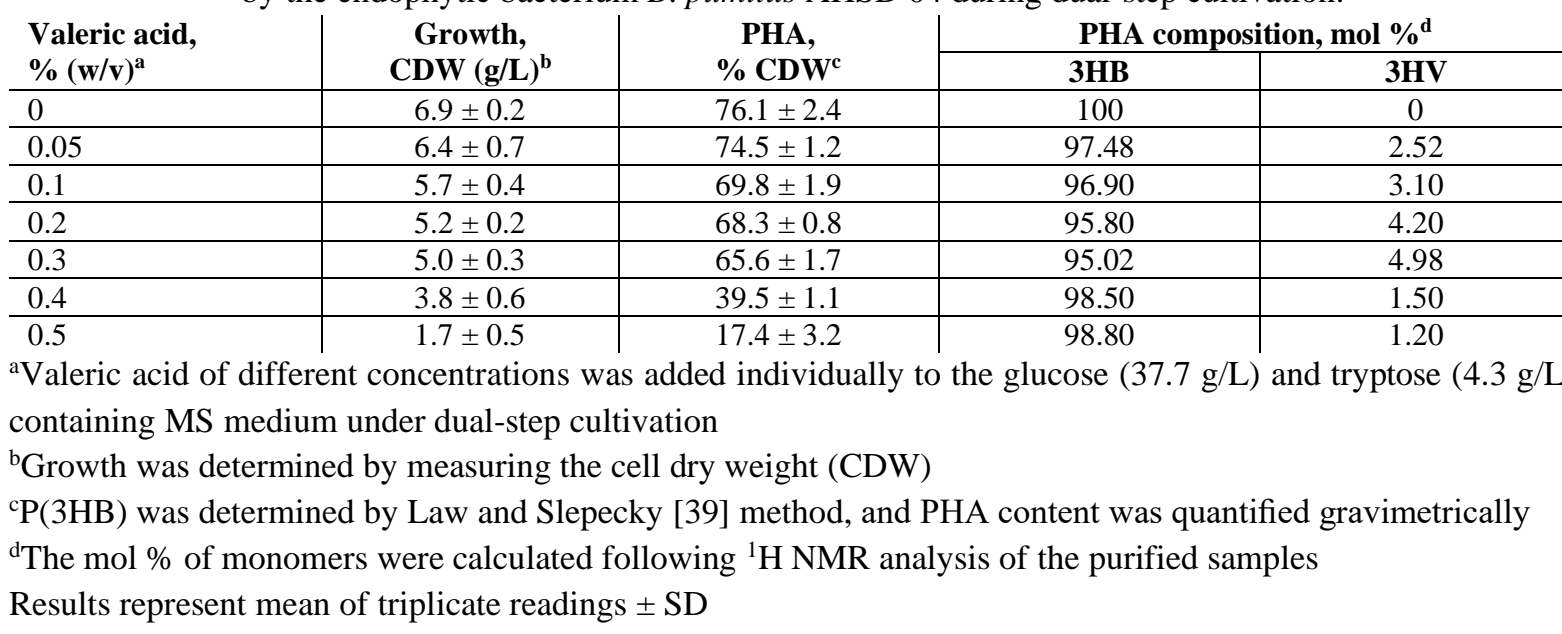

\subsection{Spectroscopic analysis of accumulated polymers.}

3.3.1. Fourier transform infrared spectroscopic analysis.

The FTIR spectra of the purified $\mathrm{P}(3 \mathrm{HB})$ (Figure 3a) revealed distinct absorption spectra for esters; - OH bending at $3429 \mathrm{~cm}^{-1}$, C-H stretching at $2930-2980 \mathrm{~cm}^{-1}$, the absorption 
band of aliphatic carbonyl $\mathrm{C}=\mathrm{O}$ at $1729 \mathrm{~cm}^{-1}$ and $-\mathrm{CH}$ group of the aliphatic compound at $1228-1383 \mathrm{~cm}^{-1}$. Likewise, the usual banding patterns at $1728 \mathrm{~cm}^{-1}$ and $1286 \mathrm{~cm}^{-1}$ for copolymer $\mathrm{P}(3 \mathrm{HB}-\mathrm{co}-3 \mathrm{HV}$ ) correspond to $\mathrm{C}=\mathrm{O}$ and $\mathrm{C}-\mathrm{O}$, respectively (Figure $3 \mathrm{~b}$ ). The other typical bands appearing at $3432 \mathrm{~cm}^{-1}, 2930-2980 \mathrm{~cm}^{-1}$, and $1228-1386 \mathrm{~cm}^{-1}$, were attributed to the $-\mathrm{OH}$ bending, $\mathrm{C}-\mathrm{H}$ stretching, and $-\mathrm{CH}$ group, respectively. However, the existence of $\mathrm{HV}$ in the co-polymer could not be definitively distinguished from HB by FTIR spectroscopic analysis [50].
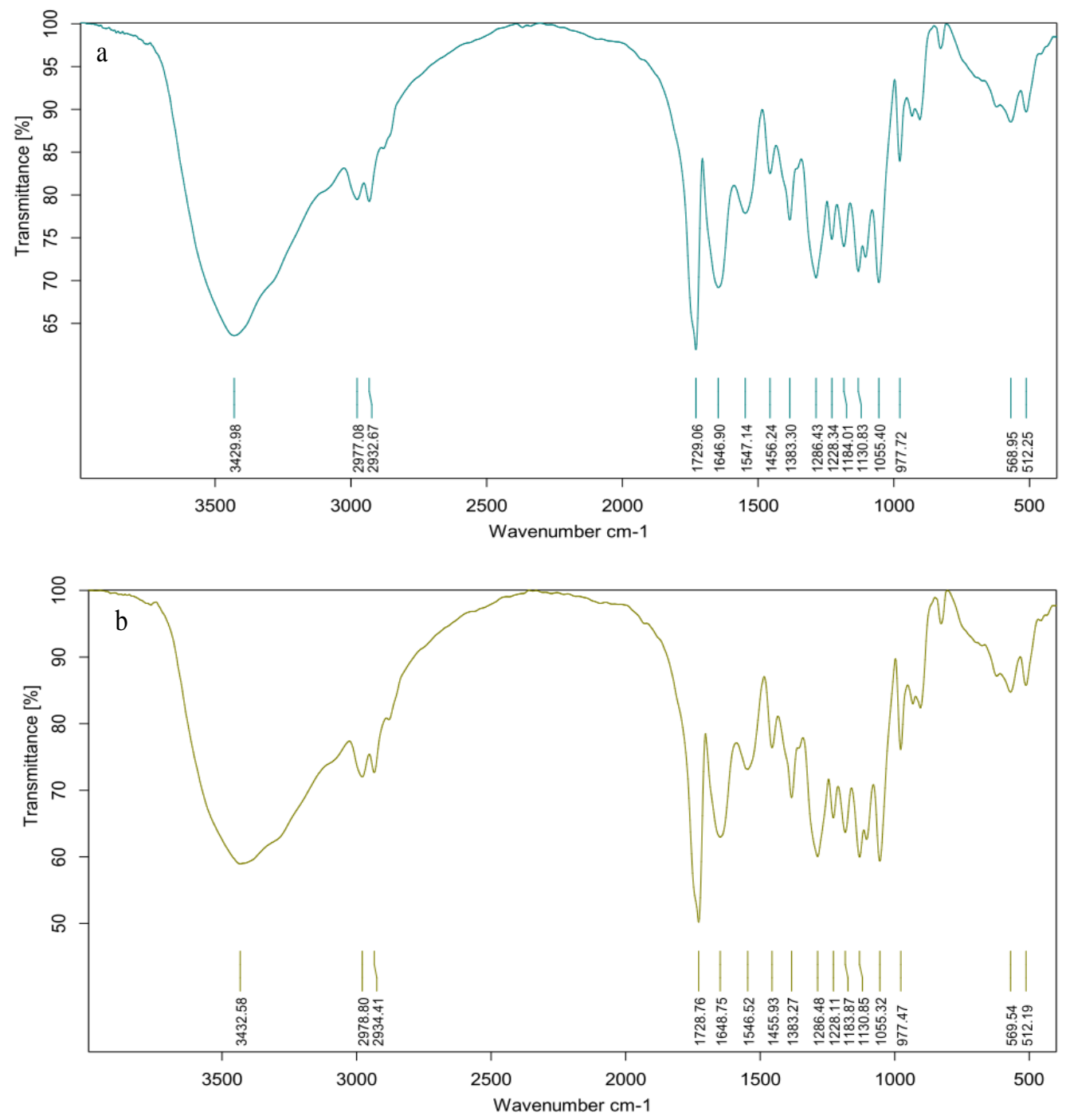

Figure 3. FTIR spectral analysis of purified (a) $\mathrm{P}(3 \mathrm{HB})$ and (b) $\mathrm{P}(3 \mathrm{HB}-\mathrm{co}-3 \mathrm{HV})$ isolated from B. pumilus AHSD 04.

3.3.2. Nuclear magnetic resonance spectroscopic analysis.

The monomeric composition of the polymers produced by B. pumilus AHSD 04 was resolved by ${ }^{1} \mathrm{H}$ NMR (at $300 \mathrm{MHz}$ ) spectral analysis. The characteristic spectrum (Figure 4a) of the purified $\mathrm{P}(3 \mathrm{HB})$ exhibited distinct chemical shifts $(\delta)$ at 1.2, 2.4- 2.6, and $5.2 \mathrm{ppm}$, which corresponds to the methyl group $\left(\mathrm{CH}_{3}\right)$ coupled to one proton, methylene group $\left(\mathrm{CH}_{2}\right)$ adjacent to an asymmetric carbon atom bearing a single proton and methylene group $(\mathrm{CH})$, respectively and confirmed the chemical structure of homopolymeric $\mathrm{P}(3 \mathrm{HB})$ [46]. On the other hand, the typical peaks at 1.2 and $0.9 \mathrm{ppm}$ as displayed in ${ }^{1} \mathrm{H}$ NMR spectrum of $\mathrm{P}(3 \mathrm{HB}-\mathrm{co}-3 \mathrm{HV})$ confirmed the presence of the methyl $\left(\mathrm{CH}_{3}\right)$ group of $3 \mathrm{HB}(95 \mathrm{~mol} \%)$ and $3 \mathrm{HV}(4.98 \mathrm{~mol} \%)$ 
monomers, respectively (Figure 4b). That the valerate was a monomeric constituent of the copolymer was confirmed by the existence of triplet at $0.9 \mathrm{ppm}[49]$.

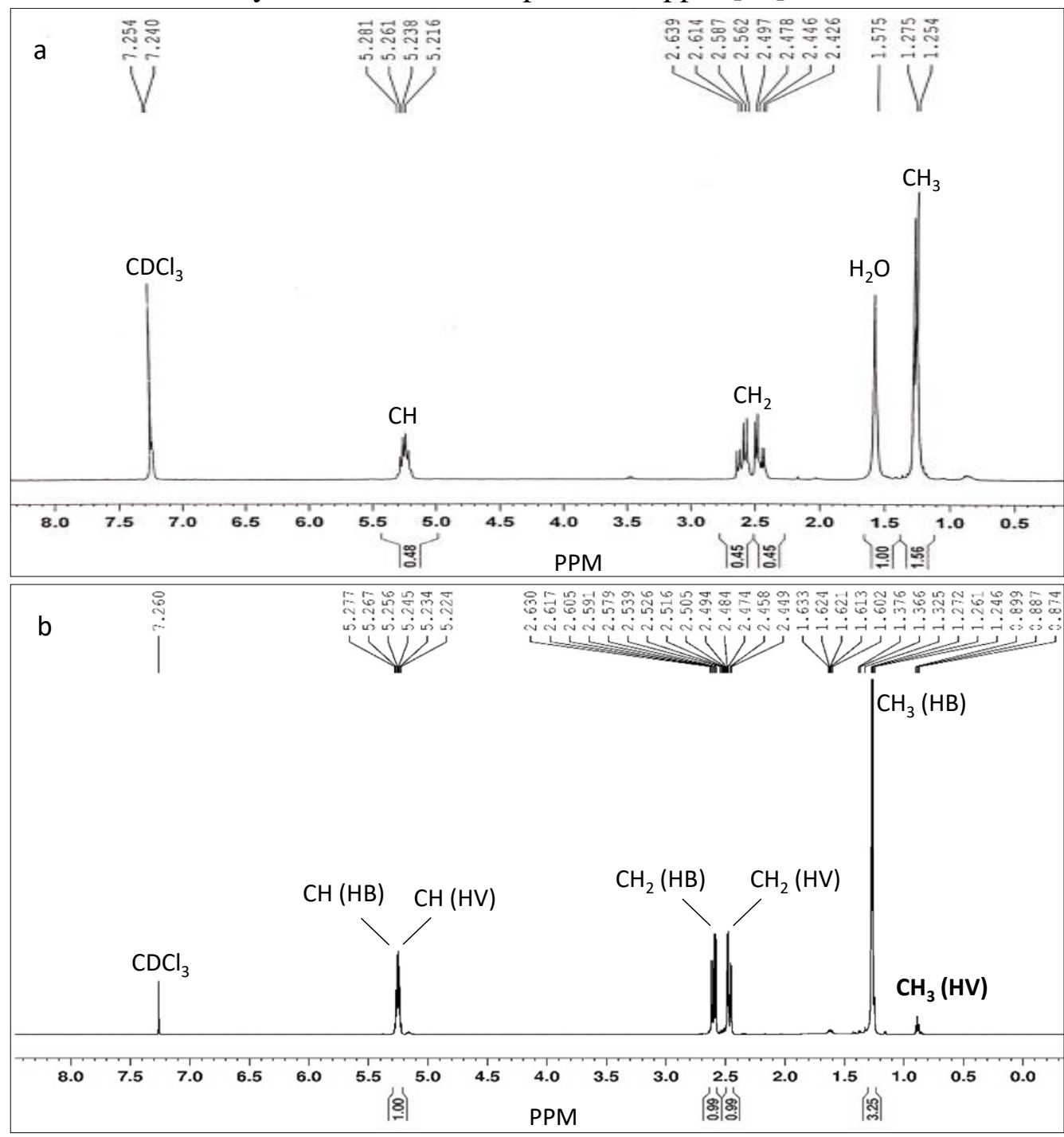

Figure 4. ${ }^{1} \mathrm{H}$ NMR spectra of (a) purified $\mathrm{P}(3 \mathrm{HB})$ and (b) $\mathrm{P}(3 \mathrm{HB}-\mathrm{co}-3 \mathrm{HV})$ isolated from B. pumilus AHSD 04.

\section{Conclusions}

This study has unveiled the potential for PHA accumulation by the seed endophytic bacterium B. pumilus AHSD 04. It showed efficient biomass as well as $\mathrm{P}(3 \mathrm{HB})$ production when the process variables were optimized following response surface methodology. Compared to the single factor system of analysis, optimization using statistical method (RSM) enhanced the $\mathrm{P}(3 \mathrm{HB})$ yield by 3.94-fold. Furthermore, the ability of the endophytic isolate to accumulate $[\mathrm{P}(3 \mathrm{HB}-\mathrm{co}-3 \mathrm{HV})]$ co-polymer during dual-step cultivation appeared to be advantageous in terms of its material properties. A more detailed analysis of the accumulated polymers is essentially warranted for fruitful utilization of this endophytic microbial resource in the future.

\section{Funding}

This research was funded by the Department of Science and Technology, New Delhi, India, in the form of INSPIRE Fellowship (Grant No. DST/INSPIRE Fellowship/REL5/2013/C1) to Rituparna Das. 


\section{Acknowledgments}

We acknowledge the technical support provided by the central instrumentation facility of the Indian Institute of Chemical Biology, Kolkata, India, for performing FTIR and NMR analysis.

\section{Conflicts of Interest}

The authors declare no conflict of interest.

\section{References}

1. Hardoim, P.R.; van Overbeek, L.S.; Berg, G.; Pirttilä, A.M.; Compant, S.; Campisano, A.; Döring, M.; Sessitsch, A. The hidden world within plants: ecological and evolutionary considerations for defining functioning of microbial endophytes. Microbiol Mol Biol Rev 2015, 79, 293-320, https://doi.org/10.1128/mmbr.00050-14.

2. Compant, S.; Cambon, M.C.; Vacher, C.; Mitter, B.; Samad, A.; Sessitsch, A. The plant endosphere worldbacterial life within plants. Environ Microbiol 2020, 23, 1812-1829, https://doi.org/10.1111/14622920.15240 .

3. Gouda, S.; Das, G.; Sen, S.K.; Shin, H.S.; Patra, J.K. Endophytes: a treasure house of bioactive compounds of medicinal importance. Front Microbiol 2016, 7, 1538, https://doi.org/10.3389/fmicb.2016.01538

4. Strobel, G. The emergence of endophytic microbes and their biological promise. J Fungi 2018, 4, 57, https://doi.org/10.3390/jof4020057

5. Kadouri, D.; Jurkevitch, E.; Okon, Y.; Castro-Sowinski, S. Ecological and agricultural significance of bacterial polyhydroxyalkanoates. Crit Rev Microbiol 2005, 31, 55-67, https://doi.org/10.1080/10408410590899228

6. Das, R.; Saha, N.R.; Pal, A.; Chattopadhyay, D.; Paul, A.K. Comparative evaluation of physico-chemical characteristics of biopolyesters $\mathrm{P}(3 \mathrm{HB})$ and $\mathrm{P}(3 \mathrm{HB}-\mathrm{co}-3 \mathrm{HV})$ produced by endophytic Bacillus cereus $\mathrm{RCL}$ 02. Front Biol 2018, 13, 1-12, https://doi.org/10.1007/s11515-018-1509-Z

7. Papik, J.; Folkmanova, M.; Polivkova, M.; Suman, J.; Uhlik, O. The invisible life inside plants: Deciphering the riddles of endophytic bacterial diversity. Biotechnol Adv 2020, 44, 107614, https://doi.org/10.1016/j.biotechadv.2020.107614.

8. Castro-Sowinski, S.; Burdman, S.; Matan, O.; Okon, Y. Natural functions of bacterial polyhydroxyalkanoates. In: Plastics from bacteria, $1^{\text {st }}$ ed.; Chen G.Q., Eds.; Microbiology monographs; Springer, Berlin, Heidelberg, Germany, 2010, 14, 39-61, https://doi.org/10.1007/978-3-642-03287-5_3.

9. Pinski, A.; Betekhtin, A.; Hupert-Kocurek, K.; Mur, L.A.J.; Hasterok, R. Defining the genetic basis of plantendophytic bacteria interactions. Int J Mol Sci 2019, 20, 1947, https://doi.org/10.3390/ijms20081947.

10. Alves, L.P.S.; do Amaral, F.P.; Kim, D.; Bom, M.T.; Gavidia, M.P.; Teixeira, C.S.; Holthman, F.; Pedrosa, F.O.; de Souza, E.M.; Chubatsu, L.S.; Müller-Santos, M.; Stacey, G. Importance of poly-3-hydroxybutyrate (PHB) metabolism to the ability of Herbaspirillum seropedicae to promote plant growth. Appl Environ Microbiol 2019, 85, e02586-18, https://doi.org/10.1128/AEM.02586-18.

11. Batista, M.B.; Teixeira, C.S., Sfeir, M.Z.T.; Alves, L.P.S.; Valdameri, G.; Pedrosa, F.O.; Sassaki, G.L.; Steffens, M.B.R.; de Souza, E.M.; Dixon, R.; Müller-Santos, M. PHB biosynthesis counteracts redox stress in Herbaspirillum seropedicae. Front Microbiol 2018, 9, 472, https://doi.org/10.3389/fmicb.2018.00472.

12. Koller, M.; Gasser, I.; Schmid, F.; Berg, G. Linking ecology with economy: insights into PHA producing microorganisms. Eng Life Sci 2011, 11, 222-237, https://doi.org/10.1002/elsc.201000190.

13. Das, R.; Dey, A.; Pal, A.; Paul, A.K. Influence of growth conditions on production of poly(3hydroxybutyrate) by Bacillus cereus HAL 03 endophytic to Helianthus annuus L. J Appl Biol Biotechnol 2016, 4, 75-84, https://doi.org/10.7324/JABB.2016.40409.

14. Das, R.; Pal, A.; Paul, A.K. Production of biopolyester poly(3-hydroxybutyrate) by Bacillus cereus RCL 02 , a leaf endophyte of Ricinus communis L. J Microbiol Biotechnol Res 2017, 7, 32-41, https://doi.org/10.24896/jmbr.2017744.

15. Archana, T.; Rajendran, L.; Manoranjitham, S.K.; Krishnan, V.P.S.; Paramasivan, M.; Karthikeyan, G. Culture-dependent analysis of seed bacterial endophyte, Pseudomonas spp. EGN 1 against the stem rot disease (Sclerotium rolfsii Sacc.) in groundnut. Egypt J Biol Pest Control 2020, 30, 119, https://doi.org/10.1186/s41938-020-00317-x. 
16. Dhole, A.; Shelat, H.; Vyas, R.; Jhala, Y.; Bhange, M. Endophytic occupation of legume root nodules by nifH-positive non-rhizobial bacteria, and their efficacy in the groundnut (Arachis hypogaea). Ann Microbiol 2016, 66, 1397-1407, https://doi.org/10.1007/s13213-016-1227-1.

17. Preyanga, R.; Anandham, R.; Krishnamoorthy, R.; Senthilkumar, M.; Gopal, N.O.; Vellaikumar, A.; Meena, S. Groundnut (Arachis hypogaea) nodule Rhizobium and passenger endophytic bacterial cultivable diversity and their impact on plant growth promotion. Rhizosphere 2021, 17, 100309, https://doi.org/10.1016/j.rhisph.2021.100309.

18. Truyens, S.; Weyens, N.; Cuypers, A.; Vangronsveld, J. Bacterial seed endophytes: genera, vertical transmission and interaction with plants. Environ Microbiol Rep 2015, 7, 40-50, https://doi.org/10.1111/1758-2229.12181.

19. Taulé, C.; Vaz-Jauri, P.; Battistoni, F. Insights into the early stages of plant-endophytic bacteria interaction. World J Microbiol Biotechnol 2021, 37, 13, https://doi.org/10.1007/s11274-020-02966-4.

20. Sobolev, C.S.; Orner, V.A.; Arias, R.S. Distribution of bacterial endophytes in peanut seeds obtained from axenic and control plant material under field conditions. Plant Soil 2013, 371, 367-376, https://doi.org/10.1007/s11104-013-1692-2.

21. Chen, L.; Shi, H.; Heng, J.; Wang, D.; Bian, K. Antimicrobial, plant growth-promoting and genomic properties of the peanut endophyte Bacillus velezensis LDO2. Microbiol Res 2019, 218, 41-48, https://doi.org/10.1016/j.micres.2018.10.002.

22. Dhouib, H.; Zouari, I.; Ben Abdallah, D.; Belbahri, L.; Taktak, W.; Triki, M.A.; Tounsi, S. Potential of a novel endophytic Bacillus velezensis in tomato growth promotion and protection against Verticillium wilt disease. Biol Control 2019, 139, 104092, https://doi.org/10.1016/j.biocontrol.2019.104092.

23. Marchut-Mikołajczyk, O.; Drożdżyński, P.; Polewczyk, A.; Smulek, W.; Antczak, T. Biosurfactant from endophytic Bacillus pumilus 2A: physicochemical characterization, production and optimization and potential for plant growth promotion. Microb Cell Fact 2021, 20, 40, https://doi.org/10.1186/s12934-02101533-2.

24. Chen, L.; Wu, Y.; Chong, X.Y.; Xin, Q.H.; Wang, D.; Bian. K. Seed-borne endophytic Bacillus velezensis LHSB1 mediate the biocontrol of peanut stem rot caused by Sclerotium rolfsii. J Appl Microbiol 2020, 128, 803-813, https://doi.org/10.1111/jam.14508.

25. Das, R.; Pal, A.; Paul, A.K. Biosynthesis and accumulation of poly(3-hydroxybutyrate-co-3hydroxyvalerate)-polyethylene glycol, a hybrid co-polymer by endophytic Bacillus cereus RCL 02. Bioprocess Biosyst Eng 2019, 42, 807-815, https://doi.org/10.1007/s00449-019-02084-y.

26. Narayanan, A.; Ramana, K.V. Polyhydroxybutyrate production in Bacillus mycoides DFC1 using response surface optimization for physico-chemical process parameters. 3 Biotech 2012, 2, 287-296, https://doi.org/10.1007/s13205-012-0054-8.

27. Penkhrue, W.; Jendrossek, D.; Khanongnuch, C.; Pathom-Aree, W.; Aizawa, T.; Behrens, R.L.; Lumyong, S. Response surface method for polyhydroxybutyrate (PHB) bioplastic accumulation in Bacillus drentensis BP17 using pineapple peel. PLoS ONE 2020, 15, e0230443, https://doi.org/10.1371/journal.pone.0230443.

28. Mohanrasu, K.; Rao, R.G.R.; Dinesh, G.H.; Zhang, K.; Prakash, G.S.; Song, D.P.; Muniyasamy, S.; Pugazhendhi, A.; Jeyakanthan, J.; Arun, A. Optimization of media components and culture conditions for polyhydroxyalkanoates production by Bacillus megaterium. Fuel 2020, 271, 117522, https://doi.org/10.1016/j.fuel.2020.117522.

29. Mohapatra, S.; Maity, S.; Dash, H.; Das, S.; Pattnaik, S.; Rath. C.C.; Samantaray, D.P. Bacillus and biopolymer: prospects and challenges. Biochem Biophys Rep 2017, 12, 206-213, https://doi.org/10.1016/j.bbrep.2017.10.001.

30. Valappil, S.P.; Misra, S.K.; Boccaccini, A.R; Keshavarz, T.; Bucke, C.; Roy, I. Large-scale production and efficient recovery of PHB with desirable material properties, from the newly characterized Bacillus cereus SPV. J Biotechnol 2007, 132, 251-258, https://doi.org/10.1016/j.jbiotec.2007.03.013.

31. Bora, L. Polyhydroxybutyrate accumulation in Bacillus megaterium and optimization of process parameters using response surface methodology. J Polym Environ 2013, 21, 415-420, https://doi.org/10.1007/s10924012-0529-z.

32. Israni, N.; Shivakumar, S. Polyhydroxyalkanoate (PHA) biosynthesis from directly valorized ragi husk and sesame oil cake by Bacillus megaterium strain Ti3: Statistical optimization and characterization. Int J Biol Macromol 2020, 148, 20-30, https://doi.org/10.1016/j.ijbiomac.2020.01.082.

33. Peña-Jurado, E.; Pérez-Vega, S.; de la Serna, F.J.Z.; Pérez-Reyes, I.; Gutiérrez-Méndez, N.; VazquezCastillo, J.; Salmeron, I. Production of poly (3-hydroxybutyrate) from a dairy industry wastewater using 
Bacillus subtilis EPAH18: bioprocess development and simulation. Biochem Eng J 2019, 151, 107324, https://doi.org/10.1016/j.bej.2019.107324.

34. Erjaee, Z.; Shekarforoush, S.S.; Hosseinzadeh, S.; Dehghani, A.; Winter, D. Identification of antifungal intracellular proteins of endophytic Bacillus pumilus by LC-MS/MS Analysis. Int J Pept Res Ther 2020, 26, 2429-2435, https://doi.org/10.1007/s10989-020-10040-8.

35. Hayat, K.; Menhas, S.; Bundschuh, J.; Zhou, P.; Niazi, N.K.; Amna; Hussain, A.; Hayat, S.; Ali, H.; Wang, J.; Khan, A.A.; Ali, A.; Munis, F.H.; Chaudhary, H.J. Plant growth promotion and enhanced uptake of Cd by combinatorial application of Bacillus pumilus and EDTA on Zea mays L. Int J Phytoremediation 2020, 22, 1372-1384, https://doi.org/10.1080/15226514.2020.1780410.

36. Das, R.; Pal, A.; Mandal, S.; Paul, A.K. Screening and production of biodegradable polyester poly(3hydroxybutyrate) by bacteria endophytic to Brassica nigra L. British Biotec J 2015, 7, 134-146, https://doi.org/10.9734/BBJ/2015/16750.

37. Das, R.; Pal, A.; Paul, A.K. Poly(3-hydroxybutyrate) production by seed endophytic Bacillus spp. of oleaginous plants. IOSR: J Biotechnol Biochem 2017, 3, 56-66, https://doi.org/10.9790/264X-03065666.

38. Ramsay, B.A.; Lomaliza, K.; Chavarie, C.; Dube, B.; Bataille, P.; Ramsay, J.A. Production of poly-( $\beta$ hydroxybutyric-co- $\beta$-valeric) acids. Appl Environ Microbiol 1990; 56, 2093-2098.

39. Law, J.H.; Slepecky, R.A. Assay of poly- $\beta$-hydroxybutyric acid. J Bacteriol 1961, 82, 33-36.

40. Tripathi, A.D.; Joshi, T.R.; Srivastava, S.K.; Darani, K.K.; Khade, S.; Srivastava, J. Effect of nutritional supplements on bio-plastics (PHB) production utilizing sugar refinery waste with potential application in food packaging. Prep Biochem Biotechnol 2019, 49, 567-577, https://doi.org./10.1080/10826068.2019.1591982.

41. Trakunjae, C.; Boondaeng, A.; Apiwatanapiwat, W.; Kosugi, A.; Arai, T.; Sudesh, K.; Vaithanomsat, P. Enhanced polyhydroxybutyrate (PHB) production by newly isolated rare actinomycetes Rhodococcus sp. strain BSRT1-1 using response surface methodology. Sci Rep 2021, 11, 1896, https://doi.org/10.1038/s41598-021-81386-2.

42. Catalan, A.I.; Ferreira, F.; Gill, P.R.; Batista, S. Production of polyhydroxyalkanoates by Herbaspirillum seropedicae grown with different sole carbon sources and on lactose when engineered to express the lacZlacY genes. Enzyme Microb Technol 2007, 40, 1352-1357, https://doi.org/10.1016/j.enzmictec.2006.10.008.

43. Kamnev, A.A.; Tugarova, A.V.; Tarantilis, P.A.; Gardiner, P.H.E.; Polissiou, M.G. Comparing poly-3hydroxybutyrate accumulation in Azospirillum brasilense Strains Sp7 and Sp245: The effects of copper(II). Appl Soil Ecol 2012, 61, 213-216, https://doi.org/10.1016/j.apsoil.2011.10.020.

44. Cardoso, A.M.; da Silva, C.V.F.; de Paula-Silva, A.S.; Padua, V.L.M. Polyhydroxybutyrate production by a sugarcane growth promoter bacterium. BMC Proc 2014, 8, 246, https://dx.doi.org/10.1186\%2F1753-6561-8S4-P246.

45. Devi, C.N.; Mazumder, P.B.; Bhattacharjee, A. Statistical optimization of polyhydroxybutyrate production by Bacillus pumilus $\mathrm{H} 9$ using cow dung as a cheap carbon source by response surface methodology. J Polym Environ 2018, 26, 3159-3167, https://doi.org/10.1007/s10924-018-1194-7

46. Werlang, E.B.; Moraes, L.B.; Muller, M.V.G.; Julich, J.; Corbellini, V.A.; de Farias Neves, F.; de Souza, D.; Benitez, L.B.; de Souza Schneider, R.C. Polyhydroxybutyrate (PHB) production via bioconversion using Bacillus pumilus in liquid phase cultivation of the biomass of Arthrospira platensis hydrolysate as a carbon source. Waste Biomass Valor 2021, 12, 3245-3255, https://doi.org/10.1007/s12649-020-01213-z.

47. Yüksekdag, Z.N.; Aslim, B.; Beyatli, Y.; Mercan, N. Effect of carbon and nitrogen sources and incubation times on poly-beta-hydroxybutyrate (PHB) synthesis by Bacillus subtilis 25 and Bacillus megaterium 12. Afr J Biotechnol 2004, 3, 63-66.

48. Suhazsini, P.; Keshav, R.; Narayanan, S.; Chaudhuri, A.; Radha, P. A Study on the synthesis of poly(3hydroxybutyrate-co-3-hydroxyvalerate) by Bacillus megaterium utilizing cheese whey permeate. J Polym Environ 2020, 28, 1390-1405, https://doi.org/10.1007/s10924-020-01687-x.

49. Akdoğan, M.; Çelik, E. Enhanced production of poly(3-hydroxybutyrate-co-3-hydroxyvalerate) biopolymer by recombinant Bacillus megaterium in fed-batch bioreactors. Bioprocess Biosyst Eng 2021, 44, 403-416, https://doi.org/10.1007/s00449-020-02452-z.

50. Shamala, T.R.; Divyashree, M.S.; Davis, R.; Lathakumari, K.S.; Vijayendra, S.V.N.; Raj, B. Production and characterization of bacterial polyhydroxyalkanoate co-polymers and evaluation of their blends by fourier transform infrared spectroscopy and scanning electron microscopy. Indian J Microbiol 2009, 49, 251-258, https://doi.org/10.1007/s12088-009-0031-z. 